\title{
BMJ Global Health Systematic review of evidence on public health in the Democratic People's Republic of Korea
}

To cite: Park JJ, Lim A-Y, Ahn H-S, et al. Systematic review of evidence on public health in the Democratic People's Republic of Korea. BMJ Glob Health 2019;4:e001133. doi:10.1136/ bmjgh-2018-001133

Handling editor Douglas James Noble

JJP and $\mathrm{A}-\mathrm{YL}$ are joint first authors.

HYS and KBP are joint senior authors.

Received 21 August 2018 Revised 3 October 2018 Accepted 6 October 2018
Check for updates

(c) Author(s) (or their employer(s)) 2019. Re-use permitted under CC BY-NC. No commercial re-use. See rights and permissions. Published by BMJ.

For numbered affiliations see end of article.

Correspondence to

Dr John J Park;

john.park@mail.harvard.edu

\section{ABSTRACT}

Background Engaging in public health activities in the Democratic People's Republic of Korea (DPRK, also known as North Korea) offers a means to improve population health for its citizens and the wider region. Such an engagement requires an understanding of current and future needs.

Methods We conducted a systematic search of five English and eight Korean language databases to identify available literature published between 1988 and 2017. A narrative review of evidence was conducted for five major categories (health systems, communicable diseases (CDs), non-communicable diseases (NCDs), injuries, and reproductive, maternal, newborn and child health (RMNCH) and nutrition).

Findings We found 465 publications on the DPRK and public health. Of the 253 articles that addressed major disease categories, we found under-representation of publications relative to proportion of disease burden for the two most significant causes: NCDs ( $54.5 \%$ publications vs $72.6 \%$ disability adjusted life years (DALYs)) and injuries ( $0.4 \%$ publications vs $12.1 \%$ DALYs), in comparison to publications on the third and fourth largest disease burdens, RMNCH and nutrition (30.4\% publications vs $8.6 \%$ DALYs) and CDs ( $14.6 \%$ publications vs $6.7 \%$ DALYs) which were over-represented. Although most disease category articles were on NCDs, the majority of NCD articles addressed mental health of refugees. Only 165 articles addressed populations within the DPRK and among these, we found publication gaps on social and environmental determinants of health, CDs, and NCDs. Conclusion There are gaps in the public health literature on the DPRK. Future research should focus on understudied, significant burdens of disease. Moreover, establishing more precise estimates of disease burden and their distribution, as well as analysis on health systems responses aimed at addressing them, can result in improvements in population health.

\section{BACKGROUND}

The continued division of the two Koreas is one of the greatest challenges for our generation, with major implications for population health for the two Koreas, the region and

\section{Key messages}

What is already known?

- The scope of published literature on public health in the Democratic People's Republic of Korea (DPRK) is currently unknown.

What are the new findings?

- There were 465 publications on the DPRK and public health.

- For articles addressing populations living inside the DPRK, we determined the proportion of papers by strategic policy area and found publication gaps on social and environmental determinants of health, communicable diseases (CDs) and non-communicable diseases (NCDs).

- For articles addressing major disease categories, relative to proportion of disease burden, we found under-representation of publications on NCDs and injuries, and over-representation of publications on reproductive, maternal, newborn and child health (RMNCH) and nutrition, and CDs.

\section{What do the new findings imply?}

- Future work should address evidence gaps, develop more accurate disease burden estimates, and analyse health systems.

globally. ${ }^{1}$ Addressing evidence gaps in public health on the Democratic People's Republic of Korea (DPRK, also known as North Korea), presents an opportunity to address the health challenges faced by its citizens and the wider region. ${ }^{2}$

The DPRK is a signatory to the Sustainable Development Goals. However, monitoring progress presents a challenge due to data quality and availability. ${ }^{34}$ The Medium Term Strategic Plan (MTSP) for the Development of the Health Sector: DPR Korea 2016-2020, includes the DPRK Government's plans to strengthen research capacity and collaboration to improve population health and use resources more efficiently. ${ }^{4}$ 


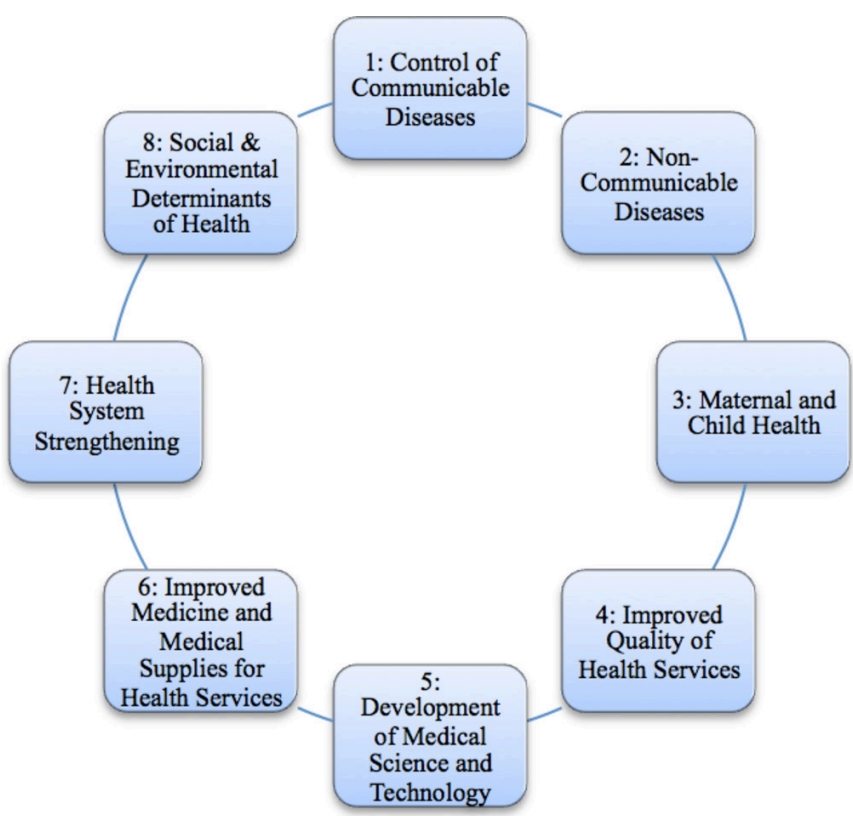

Figure 1 The DPRK Medium Term Strategic Plan 20162020: eight strategic areas. DPRK, Democratic People's Republic of Korea.

To date, no published studies have systematically reviewed the public health literature on the DPRK or examined the gap between the existing evidence and need. The objective of this study is to review the evidence gaps in public health on the DPRK across the strategic policy areas of the MTSP to inform decision makers and research.

\section{METHODS}

\section{Search strategy and selection criteria}

Policy priorities: MTSP

The DPRK-UN multi-year health plan, MTSP 2016-2020, outlines eight strategic policy areas (figure 1) and 16 research priorities (box 1) in the DPRK.

Two researchers worked independently to identify studies that examined public health issues on DPRK populations. Due to the heterogeneity of articles (eg, topics, study design, variables and outcomes), we conducted a qualitative synthesis across the major MTSP topic areas to analyse the public health themes most relevant to policymakers and researchers. Following selection of articles, two researchers independently classified and categorised articles, and assessed quality using Oxford Centre for Evidence Based Medicine Criteria-excluding level 5 articles (eg, viewpoints, perspectives, editorials, expert opinion and reports without empirical data). ${ }^{5}$ Following assessment of the articles, all empirical (including both qualitative and quantitative) articles were included due to the limited number of published studies on public health in the DPRK. DPRK or North Korean populations refer to those living within or outside the DPRK and we explored these separately. MTSP topic areas cover studies on populations living in the DPRK only, since the Government's health priorities focus on intra-DPRK health issues.
Box 1: Research agenda in DPRK MTSP 2016 - 2020

1. Quality data assessment of immunisation coverage.

2. Tuberculosis: Research on the effectiveness on the current directly observed treatment, short-course (DOTS) medicine dose.

3. Community-based knowledge, attitudes and practices (KAP) survey on reasons of immunisations dropout.

4. Research to identify different types of adverse event following immunization (AEFI) and potential reasons.

5. Prevalence of hepatitis antigen carriers.

6. Operational research for elimination of malaria.

7. Survey to assess the prevalence of schistosomiasis.

8. Technical research on meridian.

9. Research to develop and introduce new types of traditional medicine.

10. Research on nutritional status.

11. National survey on quality of air.

12. A vulnerability assessment to consider the impacts of climate change on human health in the Democratic People's Republic of Korea (DPRK).

13. National survey on quality of water.

14. Assessment of the capacity of provincial and county hospitals for emergency response.

15. Risk assessment related to various kinds of hazards.

16. Assessment of mental health service needs.

Measuring the burden of disease

The Institute of Health Metrics and Evaluation's (IHME) estimates of disability adjusted life years (DALYs) was used to estimate the burden of disease in the DPRK for 2016. IHME collates data from 68 different data sources on the DPRK (eg, WHO STEPS survey data, Unicef and World Food Programme (WFP) nutrition assessments, Multiple Indicator Cluster Survey (MICS), World Drug Report, World Malaria Report and the DPRK Government including census data) ${ }^{6}$ and is a regularly used source of data on burden of disease. The four categories (NCDs, CDs, reproductive, maternal, newborn and child health (RMNCH) and nutrition, and injuries) were selected and adapted based on disease classifications used by IHME.

We used radar diagrams to visually illustrate the gap and compare research coverage, disease burdens and research and policy priorities.

This study was not funded and no ethics approval was needed as publicly available data and publications were used. JJP had access to all English language data. AYL had access to all Korean language data. JJP, AYL, KBP and HYS are responsible for the decision to submit the manuscript.

\section{RESULTS}

\section{Description of dataset}

The initial search identified 4654 publications in 1988 to 2017; applying our inclusion and exclusion criteria yielded 465 articles for analysis (see figure 2).

We identified 220 articles addressing diseases or conditions, 77 on health systems, 49 on both health systems and diseases or conditions, and 119 on other (ie, disasters, traditional medicine, environmental health and social and behavioural health) (table 1). 


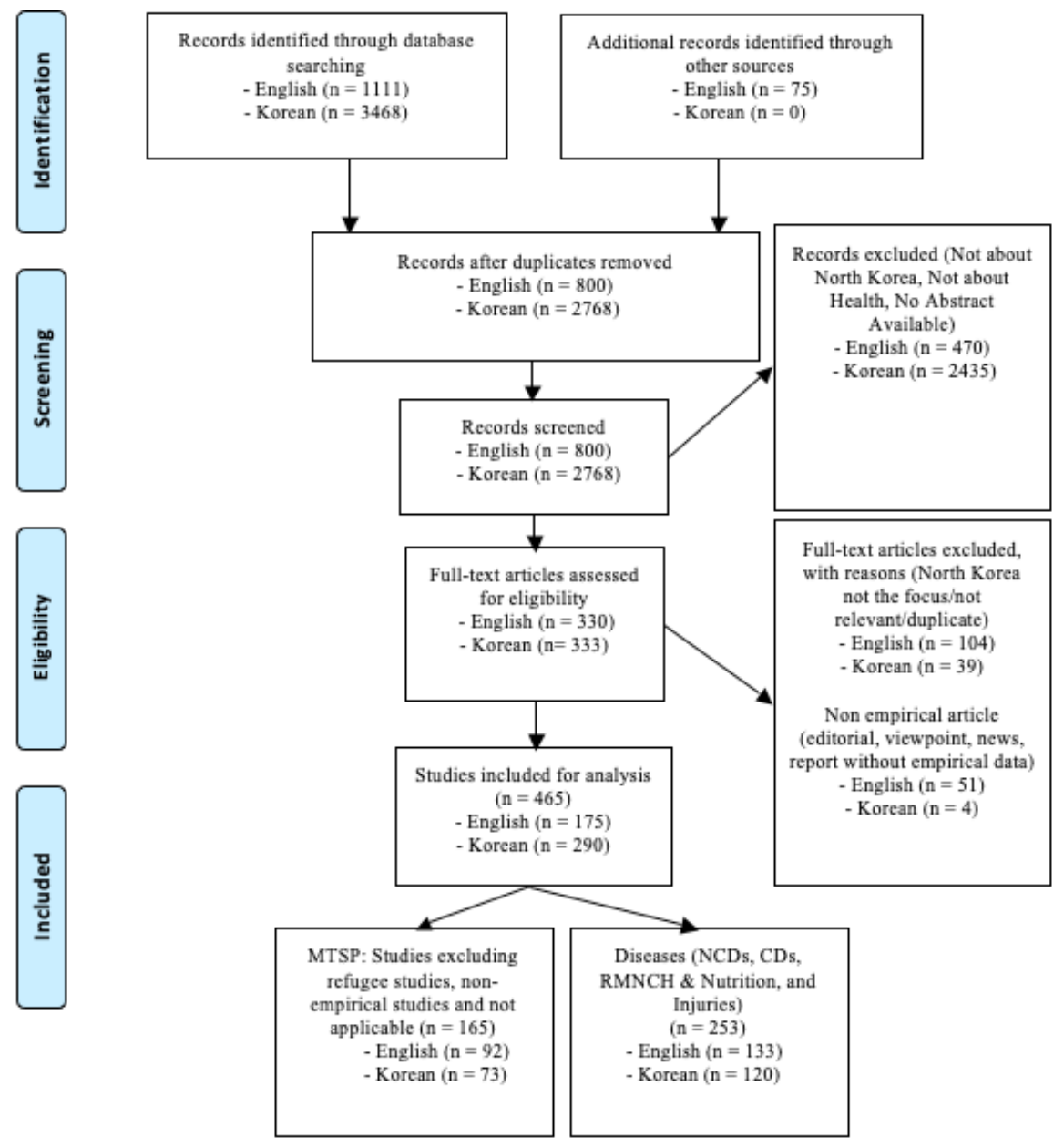

Figure 2 PRISMA flow diagram. CDs, communicable diseases; MTSP, Medium Term Strategic Plan; NCDs, noncommunicable diseases.

Of these articles, 165 addressed populations living inside the DPRK (ie, not refugee populations), which we classified under the DPRK strategic policy areas (MTSP) (figure 3). We determined the proportion of papers by MTSP area and found publication gaps in social and environmental determinants of health (MTSP 8), communicable diseases (CDs) (MTSP 1) and non-communicable diseases (NCDs) (MTSP 2) (figure 3).

Of the 16 research priorities identified by the MTSP, seven related to CDs (MTSP 1) (43.8\%), four on environment (MTSP 8) $(25.0 \%)$, three on health systems, medicines, quality and medical science and technology (MTSP

\begin{tabular}{|c|c|}
\hline Article category & Publications n (\%) \\
\hline Health systems & 77 (16.6) \\
\hline Diseases or conditions & $220(47.3)$ \\
\hline $\begin{array}{l}\text { Both health systems and diseases } \\
\text { or conditions }\end{array}$ & 49 (10.5) \\
\hline Other & $119(25.6)$ \\
\hline Total & $465(100)$ \\
\hline
\end{tabular}

$4,5,6,7)(18.8 \%)$, one on NCDs (MTSP 2) (6.3\%) and one on RMNCH and nutrition (MTSP 3) (6.3\%) (figure 3).

The eight categories used are based on the DPRK Government's strategic policy areas (MTSP). MTSP area 4, 5, 6 and 7 were grouped together, as most of these studies addressed health systems issues.

253 articles addressed NCDs, CDs, injuries, RMNCH and nutrition, inside and outside the DPRK (table 2). We compared the proportion of DALYs by disease or condition category with the proportion of publications (figure 4). We found that the proportion of publications was over-represented compared with their burden of disease for CDs $(14.6 \%$ publications vs $6.7 \%$ DALYs) and RMNCH and nutrition (30.4\% publications vs $8.6 \%$ DALYs) and under-represented for injuries $(0.4 \%$ publications vs $12.1 \%$ DALYs) and NCDs (54.5\% publications vs $72.6 \%$ DALYs) (table 2).

A narrative review of evidence was conducted for five major categories: CDs, NCDs, injuries, RMNCH and nutrition, and health systems.

\section{Communicable diseases (CDs)}

The published literature on CDs focused on tuberculosis (TB), hepatitis B and helminths. 


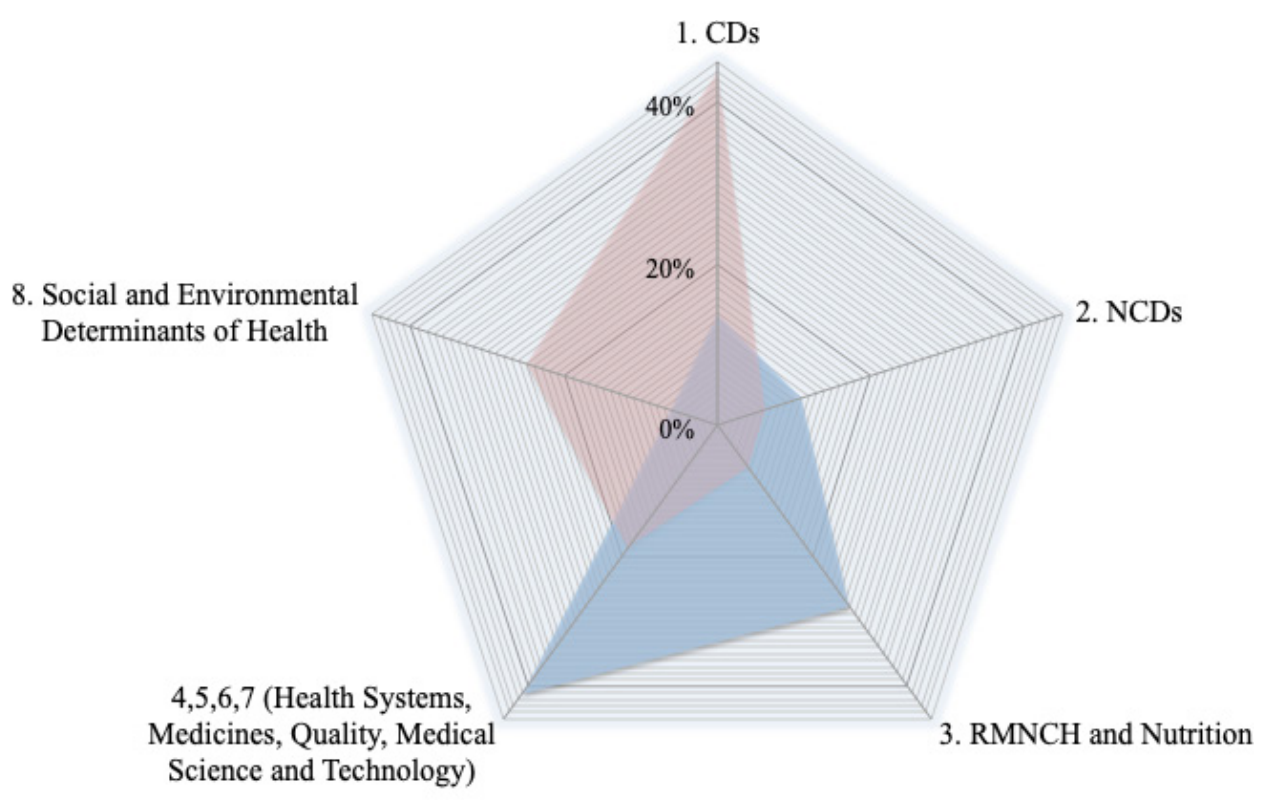

Publications \% National Research Priorities \%

Figure 3 Distribution of publications and research priorities by the DPRK strategic policy areas. CDs, communicable diseases; NCDs, non-communicable diseases; $\mathrm{RMNCH}$, reproductive, maternal, newborn and child health.

TB

One set of studies on TB relates to work of the Eugene Bell Foundation (EBF), which has supported the DPRK multidrug-resistant tuberculosis (MDR-TB) treatment programme, including providing equipment, anti-TB medications and clinical training for DPRK medical staff. $^{7}$ EBF analysis of 1 year treatment outcomes for 353 patients with rifampicin resistance showed that $250(71 \%)$ were treated successfully. ${ }^{8}$ Examination of 947 sputum samples from 667 patients between 2007 and 2009 from multiple TB sanatoria across the DPRK demonstrated high rates of resistance to first-line drugs, including isoniazid $(94.7 \%, \mathrm{n}=463)$ and rifampicin $(77.7 \%, \mathrm{n}=380)$ from 489 culture positive patients. ${ }^{9}$ EBF data has given an insight into the resistance patterns from multiple regions and regional variations including greater prevalence in

Table 2 Publications by four major disease categories which account for the largest disease burden as measured by disability adjusted life years

\begin{tabular}{lcc}
\hline Disease-specific category & Publications n (\%) & $\begin{array}{l}\text { DALYs } \\
(\%)\end{array}$ \\
\hline NCDs† & $138(54.5)$ & 72.6 \\
RMNCH and nutrition & $77(30.4)$ & 8.6 \\
CDs & $37(14.6)$ & 6.7 \\
Injuries & $1(0.4)$ & 12.1 \\
Total & $253(100)$ & 100 \\
\hline
\end{tabular}

*Disability adjusted life years for DPRK in 2016

†NCDs include dental health and mental health, as per IHME. CDs, communicable diseases; NCDs, non-communicable diseases; $\mathrm{RMNCH}$, reproductive, maternal, newborn and child health. larger cities compared with sites in smaller regions. ${ }^{9} \mathrm{EBF}$ has combined effective clinical treatment for MDR-TB with public health research to advocate for scale up of treatment and care. ${ }^{8}$

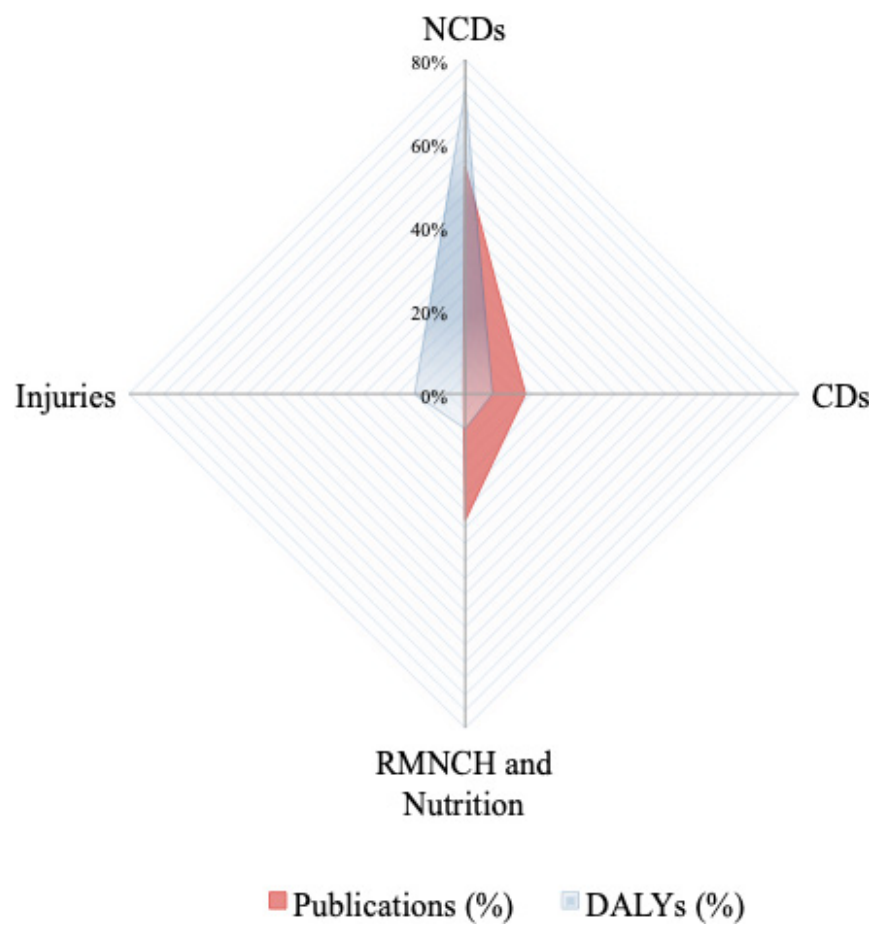

Figure 4 Distribution of publications by major disease category. CDs, communicable diseases; NCDs, noncommunicable diseases; $\mathrm{RMNCH}$, reproductive, maternal, newborn and child health; DALYs, disability adjusted life years. 
Two publications have described collaboration among Stanford University, Christian Friends of Korea and the DPRK Ministry of Public Health (MOPH) to develop the first TB reference laboratory in the DPRK in 2010, including delivery of equipment, training, and managing practical operational issues, such as problems with central power and extremes of weather. ${ }^{1011}$

Two small-scale TB studies on DPRK refugees in South Korea found high prevalence of pulmonary TB and 'severe' forms of $\mathrm{TB}^{12}$ and low levels of TB knowledge. ${ }^{13}$

\section{Hepatitis B}

A study by Unnewehr and Stich highlight the results of a nation-wide hepatitis B programme implemented by Caritas Germany and MOPH, which enabled vaccination of 3.7 million children aged 6 to 16 years old, between 2010 and 2012, achieving a coverage rate of $99.2 \%$ (3.7 million out of 3.75 million). It described collaboration on clinical training and activities to develop hepatitis B virus (HBV) prevention strategies in the DPRK. ${ }^{14}$

Lee and Park used a Markov model to establish cost effectiveness of different vaccination strategies for the prevention of perinatal HBV transmission in the DPRK and showed that selective vaccination may be more cost-effective than universal vaccination. ${ }^{15}$

One study examined 78 refugees and showed an HBsAg positive rate of $15.4 \%(\mathrm{n}=12)$ and anti-HBs positive rate of $33.3 \% \quad(\mathrm{n}=26),{ }^{16}$ and another showed low knowledge of hepatitis B among 198 refugees on a hepatitis B knowledge questionnaire. ${ }^{17}$

\section{Helminths}

Intestinal parasitic infections were examined for 236 residents and soldiers in a town bordering China and the DPRK in Hamgyeongbukdo and 46 refugees in China in 2003. It found high helminth egg positive rates among residents $(64.7 \%$; 123 out of 190$)$, while relatively lower rates were found for soldiers $(28.3 \%$; 13 out of 46$)$ and refugees in China (41.3\%; 19 out of 46$).{ }^{18}$ A team led by Seoul National University visited the DPRK over a 3-year period to promote education and knowledge transfer on diagnostics, provision of diagnostic kits and antihelminth medicines for 10000 people and treatment of 894 residents, although data was not released under a confidentiality agreement. ${ }^{19}$

\section{Non-communicable disease}

NCD is the leading burden of disease in the DPRK $(72.6 \%$ DALYs in 2016). ${ }^{6}$

\section{Prevention of NCDs}

A DPRK Government-WHO policy paper published rates for tobacco and alcohol use, elevated blood pressure (BP) and body mass index (BMI) in Pyongyang in $2005 .{ }^{20}$ Of the 2920 individuals aged 15-64 initially chosen for survey, 2655 responded (response rate 90.9\%; male: $\mathrm{n}=1316$ and female: $\mathrm{n}=1339)$. Among men, 55.8\% ( $\mathrm{n}=734)$ were smokers and $20.9 \% \quad(\mathrm{n}=275)$ were heavy drinkers (more than five drinks a day); no women reported smoking or heavy drinking. Smoking and heavy drinking prevalence rose with age. Mean BP was 131/89 for males and 129/87 for females, with a hypertension (systolic $\mathrm{BP} \geq 140 \mathrm{~mm} \mathrm{Hg}$ and/or diastolic BP $\geq 90 \mathrm{~mm} \mathrm{Hg}$ ) prevalence of $19.4 \%$ $(n=255)$ for males and $18.0 \%(n=241)$ for females. The mean BMI for males was 22.5 and 22.3 for females.

A 2013 national survey, reported in the UN-DPRK MTSP, indicate a smoking prevalence of $43.9 \%$ (adult males) - a reduction from $52.3 \%$ in $2009 .{ }^{4}$

Smoking and alcohol usage rates examined among DPRK refugees indicate similarly high rates to the South. ${ }^{21}{ }^{22}$ To deliver better prevention of NCDs, authors from the DPRK Government and WHO published a paper demonstrating the efficacy of the WHO Package of Essential Non-Communicable Disease (PEN) protocol pilot study in improving risk management of cardiovascular disease and recommended its expansion to provinces. $^{23}$

On cancer prevention, four studies explored cervical and breast neoplasms. Only one study was conducted within the DPRK, covering six provinces and purposively sampling 200 women. It showed good knowledge of cervical cancer with non-significant differences between rural $(63 \%, \mathrm{n}=62)$ and urban women $(60 \%, \mathrm{n}=61)$. However, significant gaps were identified in the usage of services, with only $6 \%(n=12)$ reporting to have had previous cervical cytology smear test. Significantly more rural women $(62 \%, \mathrm{n}=61)$ than urban women $(0 \%, \mathrm{n}=0)$ $(p<0.001)$ stated long travel distances were a barrier to accessing service facilities. ${ }^{24}$

Refugee studies based in South Korea examined the facilitators and barriers of accessing cervical cancer screening for DPRK women through qualitative interviews, ${ }^{25}$ education on breast cancer screening and rates of self-examination by surveys, ${ }^{26}$ and cervical screening rates. ${ }^{27}$

\section{Dental health}

There are 10 studies on dental health. Four papers in English examine oral health of children in Wonsan, ${ }^{28}$ knowledge of healthy oral habits in Pyongyang, ${ }^{29}$ prevalence of dental caries ${ }^{30}$ and dental caries prevention and oral health habits in Pyongyang. ${ }^{31}$ Six studies published in the Korean language examine North Korean dental terminology, ${ }^{32}$ systems, ${ }^{33}$ research trends, ${ }^{34}{ }^{35}$ education ${ }^{36}$ and dental health exchanges between the South and North. $^{37}$

\section{Mental health}

The majority of NCD papers $(\mathrm{n}=138)$ examine mental health issues $(n=110)$ on refugee populations. Most studies were conducted in South Korea, although a few studies were based in China ${ }^{38}{ }^{39}$ and Japan. ${ }^{40}$ Post-traumatic stress disorder or trauma $(n=20)$ and depression $(n=15)$ were studied most frequently. Survey respondents were usually recruited from South Korean government facilities, used databases held under the Ministry of Unification and tended to study females populations 
aged 30-50 years old-reflecting the demographics of refugees. ${ }^{41}$

\section{Reproductive, maternal, newborn and child health (RMNCH) and nutrition}

Refugee studies in South Korea have examined reproductive, maternal, newborn and child health (RMNCH) service access using surveys ${ }^{42}{ }^{43}$ and qualitative interviews. ${ }^{44}$ Although the DPRK has conducted Reproductive Health Surveys (RHS) in 1997, 2002, 2010, these were not publicly available, and there were no published studies using data from these surveys.

Nutrition has been an area of substantive research as a result of National Nutrition Surveys (NNS), led by WFP and Unicef in 1997, 1998, 2002, 2004 and 2012. ${ }^{64}$ In contrast to RHS, NNS have been subject to in-depth secondary analysis including 1997, ${ }^{46} 2002^{47}$ and 2012 surveys. ${ }^{48}$ Regional variations are measured through NNS, and in 2012, stunting prevalence remained highest in Ryanggangdo (39.6\%) compared with Pyongyang $(19.6 \%)$ which had the lowest stunting prevalence rate. ${ }^{48}$

South Korean authors have used the NNS to compare maternal nutrition among women living in North and South Korea from $2004^{49}$ and 2012 surveys. ${ }^{50}$ A study conducted in 1997 examined 3984 children under 7 years of age in 40 Government-selected institutions to identify the prevalence of acute malnutrition across four provinces $(16.5 \%, \mathrm{n}=654$, out of total of 3965 , as 19 children with weight-for-height $Z$-score $<-4.0$ were excluded) and chronic malnutrition $(38.2 \%, \mathrm{n}=1513$, out of a total of 3960 as 24 children with heightfor-age Z-score $<-5.0$ were excluded). ${ }^{46}$ Schwekendiek has conducted in-depth analysis using NNS data by comparing regional ${ }^{51}$ and seasonal variations in malnutrition in the DPRK, ${ }^{52}$ height-weight differences of North and South Korean children, ${ }^{5354}$ determinants of nutritional status, ${ }^{55}$ and nutritional impact during the famine. ${ }^{56}$

In contrast to several observational, cohort and secondary data analysis studies, only one randomised controlled trial was identified. The authors (all from the DPRK) recruited 234 infants aged 6-12 months from 36 nurseries in the DPRK and demonstrated that iron supplementation to rice group was superior to placebo, reducing prevalence of anaemia $(24.3 \%$ vs $48.1 \%, \mathrm{p}<0.01)$ and increasing Hb levels $(117.6 \mathrm{~g} / \mathrm{L}$ vs $109.8 \mathrm{~g} / \mathrm{L}, \mathrm{p}<0.001)$ and serum ferritin levels (40.7 vs $26.8 \mathrm{mcg} / \mathrm{L}, \mathrm{p}<0.001) .{ }^{57}$

There were several malnutrition studies on iodine deficiency and hypothyroidism. ${ }^{58-60}$ The first comprehensive national iodine deficiency survey conducted between 2009-2010 by the DPRK Institute of Child Nutrition, with assistance from the International Council for Control of Iodine Deficiency Disorders and WHO, examined rates among 1200 children aged 6-12 years from 30 clusters (40 children in each cluster). The total goitre rate was $19.5 \%(\mathrm{n}=234)$ nationally, and by province it was highest in Ryanggangdo (30.8\%) and lowest in Pyongyang (11.8\%). ${ }^{61}$

\section{Health system}

Health system strengthening (HSS) is a health policy priority; yet, few studies have analysed the health system in the DPRK. ${ }^{4}$ Grundy and Moodie provide an analysis of the current health system and strategic frameworks to adopt for further strengthening. ${ }^{62}$ However, studies analysing the DPRK health system are mainly by South Korean authors. Health system studies have examined broad political, legislative and economic conditions $^{63-70}$ including analysis of potential unification scenarios that could involve the integration of the health systems, ${ }^{71-73}$ as well as drawing on comparative analysis from German unification and transitions of former Soviet bloc states. ${ }^{74-76}$

International organisations' reports offer insight into the health system. WHO provides a HSS analysis in its Country Cooperation Strategy (CCS) ${ }^{77}$ and Unicef publishes annual reports, ${ }^{78}$ analysis of the situation of children and women in the DPRK $^{79}$ and MICS data, ${ }^{80}$ outlining the broader systems and data challenges facing RMNCH populations. Amnesty International produced a report on the North Korean health system ${ }^{81}$ and nutrition issues ${ }^{82}$ based on interviews with refugees and experts. Drawing from an operational perspective, Médecins Sans Frontières published a 189-page report detailing activities and challenges working in the DPRK using excerpts from emails, fax and interviews while working in the DPRK between 1995 and $1998 .^{83}$ Moreover, the Global Alliance for Vaccines and Immunization has made their documentation on in-country activities publicly available. ${ }^{84}$

\section{DISCUSSION}

To our knowledge, this is the first systematic review and narrative synthesis of the published literature on public health in the DPRK. Earlier analysis was limited in scope and explored English language articles published by DPRK authors from 1997 to $2017,{ }^{85}$ refugee populations, ${ }^{86-88}$ or DPRK Journals only. ${ }^{89-91}$ Research and policy development should be informed by evidence, ${ }^{77}$ yet we identified gaps in evidence.

The DPRK faces a triple burden of disease from NCDs, CDs and injuries and disasters. Increasingly, NCDs form the major burden of disease in the DPRK. NCDs are a major contributor towards the increase in life expectancy gap between the North and South. ${ }^{92}$ The MOPH has already developed a national strategic plan for prevention and control of NCDs ${ }^{93}$ recently updated for 2014-2020. ${ }^{94}$ However, only 1 of the 16 MTSP research priorities was on NCDs (mental health). We identified 138 articles addressing NCDs and the vast majority $(n=110)$ explored the mental health of people living outside the DPRK and hence offer limited inference about populations living in the DPRK. Future NCD 
research could focus on cardiovascular disease, cancer and respiratory disease-which constitute a significant share of the estimated NCD burden in the DPRK.

CDs still account for a large proportion of disease burden; research on this area will remain an important part of a national $\mathrm{CD}$ control strategy. There were several studies on MDR-TB and hepatitis, but none on HIV. Recent publications including the DPRK TB prevalence survey, ${ }^{95}$ national malaria strategy, ${ }^{96}$ and malaria programme review ${ }^{97}$ provide opportunities to better understand and control CD.

There was only one report on injuries, although injuries constitute $12.1 \%$ of disease burden (in DALYs, 2016). The DPRK Government has selected the months of November and May as Accident Prevention Months, promoting efforts to reduce traffic and fire injuries through education and prevention programs. ${ }^{4}$ Moreover, one MTSP research priority is on injuries. However, research is needed to characterise and reduce the rates of injuries, occupational hazards and work related-illness.

In $\mathrm{RMNCH}$, there have been limited published studies despite Unicef's role in the DPRK and WHO's Improving Women and Child Health programme. Research is needed to more precisely measure changes to maternal, infant and under-5 mortality rates and to identify interventions to further improve them. ${ }^{4}$ In particular, there is a need for studies that evaluate the impact of programmes and policy interventions, and studies on RMNCH knowledge, access, utilisation and outcomes. The 2017 MICS, published by the Government's Central Bureau of Statistics and Unicef in June 2018-the first since 2009-represents progress in data collection in child and women health in the DPRK ${ }^{80}$ Moreover, the 2014 Socio-Economic, Demographic and Health Survey, published by the Central Bureau for Statistics and UNFPA, also provides data on RMNCH. ${ }^{98}$

There was limited health systems analysis from the DPRK. According to the MTSP, the DPRK health system faces challenges in delivering basic 'operational funds, infrastructure, referral systems and logistics'. ${ }^{4}$ Engaging in health system research with policymakers represents an opportunity to improve population health.

\section{Limitations of this study}

We have identified six limitations of our study. First, we attempted to identify all empirical (qualitative and quantitative) articles on public health in DPRK populations. Of the 465 studies included (1988-2017), 294 (63.2\%) were published in 2010 or afterwards, suggesting increasing scholarly interest in health research on DPRK populations. However, the heterogeneity of articles meant conducting a quantitative synthesis was not possible. We classified study quality by Oxford Evidence Level, but did not assess inherent article quality (eg, bias). Over half $(\mathrm{n}=241 ; 51.8 \%)$ of articles were qualitative or mixed methods studies. Many studies used cohort or cross-sectional designs and were based on self-reported data. Although the majority were original empirical studies $(\mathrm{n}=246 ; 52.9 \%)$, a large proportion relied only on previous empirical studies $(\mathrm{n}=190 ; 40.9 \%)$.

Second, the distribution of included studies was skewed towards the refugee population (142 of 290 Korean articles and 79 of 175 English articles) with the majority of refugee studies focused on those living in South Korea. Studies on refugee populations were often small, limiting generalisability. Only 165 of the 465 articles (35.5\%) were directly on populations living within the DPRK. 25 articles $(5.4 \%)$ articles included an author from the DPRK, compared with 376 articles (80.9\%), which had a first author from South Korea.

Third, we were unable to search DPRK journals. It would be of interest to determine the degree of overlap of articles and topics with articles from the DPRK. ${ }^{89}$ Moreover, several South Korean articles had English abstracts but not all articles did, limiting accessibility to an international audience.

Fourth, burden of disease estimates were obtained from IHME. ${ }^{6}$ Although IHME estimates are derived from a limited data sample, often using secondary data analysis, since there is limited publicly available health data, it remains an important source of information on public health in the DPRK.

Fifth, not all health policy topics (e.g. social determinants of health) and articles were included in the narrative review due to space constraints.

Sixth, this study is limited by the date range we searched; some relevant articles could have been published earlier and additional articles will be written in the future.

While these limitations reduce the generalisability of findings beyond the populations studied and indicate the need for high-quality studies in settings within the DPRK, to our knowledge, this study offers the most comprehensive overview of the literature published on DPRK populations to date.

\section{CONCLUSION}

In sum, we found gaps in the public health evidence on the DPRK.

Further research should focus on addressing evidence gaps on the most significant and under-studied burdens of disease. In addition, obtaining more accurate estimates on magnitude and distribution of disease burden, and analysis on health systems, can contribute towards future gains in population health.

There are significant opportunities to improve health in the DPRK and wider region - a better understanding of public health through data collection, knowledge and research can help achieve this goal.

\section{Author affiliations}

${ }^{1}$ Harvard T.H. Chan School of Public Health, Boston, Massachusetts, USA

${ }^{2}$ Institute for Health and Unification Studies, Seoul National University College of

Medicine, Seoul, Republic of Korea

${ }^{3}$ Harvard Medical School, Boston, Massachusetts, USA

${ }^{4}$ Tufts University School of Medicine, Boston, Massachusetts, USA

${ }^{5}$ University of Maryland School of Medicine, Baltimore, Maryland, USA 
${ }^{6}$ University of Pennsylvania, Philadelphia, Pennsylvania, USA

${ }^{7}$ Yonsei University College of Medicine, Seoul, Republic of Korea

Contributors JJP, KBP, HYS, AYL, SYC and HSA conceived and designed the study. JJP, OLP, DHO, AYL, SYC and HSA searched the literature. SJJ offered statistical support. JJP, DHO, OLP, AIK, SYK, AYL, SYC and HSA extracted, analysed and interpreted the results. JJP drafted the initial report. AYL, SYC and HSA commented on the first draft, and RA and JBB revised the draft. All authors critically commented on and revised subsequent versions of the report.

Funding The authors have not declared a specific grant for this research from any funding agency in the public, commercial or not-for-profit sectors.

Competing interests None declared.

Patient consent for publication Not required.

Provenance and peer review Not commissioned; externally peer reviewed.

Data sharing statement № additional data are available.

Open access This is an open access article distributed in accordance with the Creative Commons Attribution Non Commercial (CC BY-NC 4.0) license, which permits others to distribute, remix, adapt, build upon this work non-commercially, and license their derivative works on different terms, provided the original work is properly cited, appropriate credit is given, any changes made indicated, and the use is non-commercial. See: http://creativecommons.org/licenses/by-nc/4.0

\section{REFERENCES}

1. Park JJ, Park KB, Shafik N. Nuclear war and public health: rebalancing priorities and global health leadership. Lancet 2017;390:1733-4.

2. Park JJ, Shin HY, Atun R. Global health engagement with North Korea. BMJ 2018;361.

3. WHO SEARO. 2017 Health SDG Profile: Democratic People's Republic of Korea. Available: http://www.searo.who.int/entity/health situation_trends/countryprofile_dprk.pdf?ua $=1$

4. DPR Korea Ministry of Public Health. Medium term strategic plan for the development of the health sector: Dpr Korea 2016-2020. Pyongyang: DPR Korea Ministry of Public Health, 2017.

5. Oxford centre for evidence-based medicine - levels of evidence (March 2009). Available: https://www.cebm.net/2009/06/oxfordcentre-evidence-based-medicine-levels-evidence-march-2009/

6. Institute for Health Metrics and Evaluation, University of Washington Global Burden of Disease Study 2016 (GBD 2016) data input sources tool, 2018. Available: http://ghdx.healthdata.org/gbd-2016/ data-input-sources?page $=1$ \&locations $=7$ \&components $=-1$

7. Seung KJ, Linton SW. The growing problem of multidrug-resistant tuberculosis in North Korea. PLoS Med 2013;10:e1001486.

8. Seung KJ, Franke M, Linton SW. Multidrug-resistant tuberculosis treatment in North Korea: is scale-up possible? PLoS Med 2016;13:e1002062.

9. Jung J, Jegal Y, Ki M, et al. Characteristics of drug resistant tuberculosis in sanatoria of North Korea. J Korean Med Sci 2017;32:1105-10.

10. Perry S, Gresham L, Linton H, et al. Engaging North Korea on mutua interests in tuberculosis control. Korea Economic Institute Academic Paper Series 2011;6:1-13.

11. Perry S. The Stanford North Korean Tuberculosis Project. In: Shin GW, Lee KJ, eds. U.S.-DPRK educational exchanges: assessment and future strategy. Stanford CA: Walter H. Shorenstein Asia-Pacific Research Center Books, 2011: 121-6.

12. Choi C-M, Jeung W-K, Kang C-I, et al. Clinical characteristics of tuberculosis in North Korean refugees. Tuberc Respir Dis 2006;60:285-9.

13. Lee IS, Park HR. The knowledge \& attitude on tuberculosis by parents of North Korean refugee children. Child Health Nurs Res;21:216-26.

14. Unnewehr M, Stich A. Fighting hepatitis B in North Korea: feasibility of a Bi-modal prevention strategy. J Korean Med Sci 2015;30:1584-8.

15. Lee $D$, Park SM. Cost-effectiveness analysis of hepatitis $B$ vaccination strategies to prevent perinatal transmission in North Korea: selective vaccination vs. universal vaccination. PLoS One 2016;11:e0165879.

16. Choi HR, Kim BS, Won JW. HBsAg and anti-HBs prevalence in North Korean defectors. Korean J Fam Med 1999;20:1778-83.

17. Park MJ, Jeon JH, Song HJ. Awareness and knowledge about hepatitis B among North Korean immigrants. Korean J Rehabil Nurs 2016;19:64-70.
18. Li S, Shen $\mathrm{C}$, Choi MH, et al. Status of intestinal helminthic infections of borderline residents in North Korea. Korean J Parasitol 2006;44:265-8.

19. SNU. White paper: control of intestinal parasites of North Korean people by transfer of South Korean technology and strategy. Seoul: Seoul National University, College of Medicine, Department of Parasitology, 2008

20. Choe TC. Final report of non-communicable disease (NCD) risk factor survey in Moranbong district of Pyongyang, DPR Korea. WHO, 2006. Available: http://www.searo.who.int/entity/ noncommunicable_diseases/data/DPRK_2005_STEPS_Survey Report.pdf?ua $=1$

21. Kim YK. A survey on the health status of North Korean refugees in a region. J Korean Soc Emerg Med Technol 2009;13:5-18.

22. Song HJ, Song MS. Alcohol drinking behavior and related factors among North Korean refugees. J Korean Alcohol Sci 2012;13:89-98.

23. Hyon CS, Nam KY, Sun HC, et al. Package of essential noncommunicable disease (Pen) interventions in primary health-care settings in the Democratic people's Republic of Korea: a feasibility study. WHO South East Asia J Public Health 2017;6:69-73.

24. Tran NT, Choe SI, Taylor R, et al. Knowledge, attitude and practice (KAP) concerning cervical cancer and screening among rural and urban women in six provinces of the Democratic People's Republic of Korea. Asian Pac J Cancer Prev 2011;12:3029-33.

25. Kim K, Kim S, Chung Y. A qualitative study exploring factors associated with Pap test use among North Korean refugees. Health Care Women Int 2017;38:1115-29.

26. Hyun MY, Song HJ, Lee EJ, et al. Predictors of breast self examination practice among North Korean immigrant women. Korean J Health Promot 2015;15:9-15.

27. Park J, Kim H, Yang W, et al. Cervical cancer screening and its associated factors among North Korean Defectors living in South Korea. J Immigr Minor Health 2018;20:66-72.

28. Goe LC, Baysac MA, Todd KH, et al. Assessing the prevalence of dental caries among elementary school children in North Korea: a cross-sectional survey in the Kangwon Province. Int J Dent Hyg 2005;3:112-6.

29. Tarvonen PL, Sipilä K, Ri YS, et al. Awareness of and compliance with healthy oral habits reported by children and their parents in Democratic People's Republic of Korea after a preventive programme. Acta Odontol Scand 2016;74:525-31.

30. Tarvonen PL, Sipilä K, Yang GS, et al. Comparison of two preventive interventions on dental caries among children in Democratic People's Republic of Korea. Int J Dent Hyg 2016;14:301-6.

31. Tarvonen PL, Suominen AL, Yang GS, et al. Association between oral health habits and dental caries among children in Pyongyang, Democratic People's Republic of Korea. Int J Dent Hyg 2017;15:e136-42.

32. Huh JY, Lee EU. Comparison of dental terminology between South and North Korea. J Korean Dent Assoc 2000;38:741-51.

33. Koh DH, Koh SH, Kim HR. Comparison of the dental health system between Dental Health System between South and North Korea (I) (translated from "남북한 구강보건의료 도의 비교(I)"). J Korean Dent Assoc 1998;36:204-14.

34. Kim SH, Kim MG, Myoung H. A study on the North Korea's clinical dentistry system and research tendency of dentistry. J Korean Dent Assoc 2015;53:712-25.

35. Huh JY, Kim TY, Lee EU. Analysis of dental articles published in North Korean medical journals. (translated from "북한 의학 학 지에 게재된 치의학 논문의 분석"). J Korean Dent Assoc 2002;40:532-41.

36. Shin TJ, Han DH, Jin BH. A study on the North Korea's dentistry education system and its implication on the direction for integration of South and North Korea's dentistry education. J Korean Dent Assoc 2015;53:726-31.

37. Han DH, Shin TJ, Myoung H. Current status and prospects of oral health services exchange from South and North Korea through nongovernmental organizations. J Korean Dent Assoc 2015;53:705-11.

38. Yu SE, Jeon WT. Mental health of North Korean refugees in protective facilities in China. Psychiatry Investig 2008:5:70-7.

39. Lee $\mathrm{Y}$, Lee MK, Chun KH, et al. Trauma experience of North Korean refugees in China. Am J Prev Med 2001;20:225-9.

40. Lee $\mathrm{CH}$, Min SK, Jeon WT, et al. Mental health and quality of life of North Korean defectors living in Japan. Asian J Psychiatr 2009;2:95-9.

41. Republic of Korea Government. Ministry of unification. Status of North Korean Defectors. Available: www.unikorea.go.kr/unikorea/ business/NKDefectorsPolicy/status/lately/

42. Hwang NM, Kim SW, Choi JS. Women of a unified Korea. Women and child health policy challenges and implementation strategies. Translated from "통일한국의 여성 아동 건강 책과 와 추진 략". Korean 
Women's Development Institute. Korea Institute for Health and Affairs, 2015.

43. Kim HS, Lee HW, Park SM. Survey of North Korea's maternal and newborn health management through North Korean Defectors. $J$ Korean Soc Matern Child Health 2015;19:37-46.

44. Kim SH, Park MJ. The practice of women and social structure on the reproductive sphere in North Korea: the reproduction-related legislations and women's experience. Women's Studies Review 2016;33:99-134.

45. DPRK. Final report of the national nutrition Survey 2012. DPRK 2013.

46. Katona-Apte J, Mokdad A. Malnutrition of children in the Democratic People's Republic of North Korea. J Nutr 1998;128:1315-9.

47. Hoffman DJ, Lee SK. The prevalence of wasting, but not stunting, has improved in the Democratic People's Republic of Korea. J Nutr $2005 ; 135: 452-6$

48. Kim JE. Nutritional state of children in the Democratic People's Republic of Korea (DPRK): based on the DPRK final report of the national nutrition Survey 2012. Pediatr Gastroenterol Hepatol Nutr 2014;17:135-9.

49. Shim JE, Yoon J, Jeong SY. Status of early childhood and maternal nutrition in South Korea and North Korea. Korean J Community Nutr 2007:12:123-32.

50. Yun S-Y, Kwon YH, Yoon J. Status of maternal nutrition in South and North Korea. Korean J Community Nutr 2016;21:265-73.

51. Schwekendiek D. Regional variations in living conditions during the North Korean food crisis of the 1990s. Asia Pac J Public Health 2010;22:460-76.

52. Schwekendiek $D$. The effect of the seasons of the year on malnutrition in North Korea. Homo 2009;60:59-75.

53. Schwekendiek D, Pak S. Recent growth of children in the two Koreas: a meta-analysis. Econ Hum Biol 2009;7:109-12.

54. Schwekendiek D. Height and weight differences between North and South Korea. J Biosoc Sci 2009:41:51-5.

55. Schwekendiek D. Determinants of well-being in North Korea: evidence from the post-famine period. Econ Hum Biol 2008;6:446-54.

56. Schwekendiek D. The North Korean standard of living during the famine. Soc Sci Med 2008;66:596-608.

57. $\operatorname{Rim~H}, \mathrm{Kim} \mathrm{S}, \mathrm{Sim} \mathrm{B}$, et al. Effect of iron fortification of nursery complementary food on iron status of infants in the DPRKorea. Asia Pac J Clin Nutr 2008;17:264-9.

58. Chung HR. lodine and thyroid function. Ann Pediatr Endocrinol Metab 2014;19:8-12.

59. Kim JH, Park SA, Kim NH, et al. Thyroid dysfunction of North Korean women living in South Korea, focusing on subclinical hypothyroidism. Endocrinol Metab 2012;27:200-7.

60. Yadav K. Iodine deficiency in the Democratic People's Republic of Korea. IDD Newsletter November 2012. Korea: IDD, 2012.

61. DPRK. Report on iodine deficiency disorders survey in DPR of Korea 2010.

62. Grundy J, Moodie R. An approach to health system strengthening in the Democratic Peoples Republic of Korea (North Korea). Int $J$ Health Plann Manage 2009;24:113-29.

63. LeeMG, Jeong UG. A positive study on the social security system of North Korea: with a focus on actual operation of health care security system. The Korean Association of North Korean Studies 2003;7:209-36.

64. Kim JS. A Study on the Characteristics and Limitations of North Korea's Pharmaceutical Policy. Health and Social Welfare Review 2012;32:631-65.

65. Kim JS. The political economy of North Korea: impacts on the pharmaceutical policy. Korean J Unification Affairs 2012;24:107-42.

66. Barrett J. The North Korean healthcare system: on the fine line between resilience and vulnerability. Resilience: Interdisciplinary Perspectives on Social and Humanitarianism 2011;2:52-65.

67. Min HJ, Jeong HS, Kim SM. Qualitative study on North Korea's healthcare system and healthcare use: based on experiences of refugees in the 2010s. Korean Soc Secur Stud 2015;31:53-81.

68. Grundy J, Hoban E, Allender S, et al. The inter-section of political history and health policy in Asia--the historical foundations for health policy analysis. Soc Sci Med 2014;117:150-9.

69. Shin HY, Lee HW, An KS, et al. North Korea's trends on healthcare system in Kim Jong Un era: concentrated on healthcare delivery and organizational system. Journal of Peace and Unification Studies 2016;8:181-211.

70. Kwon MO, Kim HW, Yu JA, et al. Military healthcare system of North Korea. J Mil Nurs Res 2016;34:1-11.
71. Lee SB. The healthcare system and outcomes of North Korea: a comparative analysis on the International level. Korean J Pol Sci 2010;17:79-97.

72. Park IW, Moon OR. Policy issues and directions for the integration of North and South Korean health care system. Health and Social Welfare Review 1994;14:163-89.

73. Lee YH, Yoon SJ, Kim SH, et al. A strategy toward reconstructing the healthcare system of a unified Korea. J Prev Med Public Health 2013;46:134-8.

74. Bae HS. A study on the tasks of medical security for the coming unified Korea: lessons from the changes of medical security in Eastern Europe in transition. Korean J Unification Affairs 2005;17:113-38.

75. Kim SC. Looking for social welfare system after the Korean Peninsula reunification: possibility of adopting German case. Ordo Econ J 2016;19:17-39.

76. Ryu GC. Lessons from unified Germany and their implications for healthcare in the unification of the Korean Peninsula. J Prev Med Public Health 2013;46:127-33.

77. WHO Country Office for DPR Korea. WHO country cooperation strategy Democratic People's Republic of Korea 2014-2019. Pyongyang: WHO Country Office for DPR Korea, 2016.

78. UNICEF. UNICEF Annual Report DPRK. UNICEF, 2016.

79. UNICEF. Situation analysis of children and women in the Democratic People's Republic of Korea - 2017. Pyongyang: UNICEF, 2016.

80. Central Bureau of Statistics of the DPR Korea and UNICEF. DPR Korea multiple indicator cluster survey 2017, survey findings report. Pyongyang, DPR Korea: Central Bureau of Statistics and UNICEF, 2017.

81. Amnesty International. The Crumbling state of health care in North Korea. London: Amnesty International Publications, 2010.

82. Amnesty International. Starved of rights: human rights and the food crisis in the Democratic People's Republic of Korea (North Korea). London: Amnesty International Publications, 2004.

83. Médecins Sans Frontières. MSF and North Korea 1995-1998. MSF speaking out. MSF, October 2014. Available: https://reliefweb.int/ sites/reliefweb.int/files/resources/COREE\%20du\%20NORD_VA. pdf

84. GAVI. DPR Korea proposals, reports \& plans. Available: https://www. gavi.org/country/dpr-korea/documents/

85. Jeong GH, Huh S. Bibliometric and content analysis of medical articles in the PubMed database published by North Korean authors from 1997 to July 2017. Sci Ed 2017:4:70-5.

86. Lee Y, Lee M, Park S. Mental health status of North Korean refugees in South Korea and risk and protective factors: a 10-year review of the literature. Eur J Psychotraumatol 2017;8.

87. Yang OK, Yun JH. Scoping review on the mental health studies of North Korean defectors in Korea. Multiculture \& Peace 2017;11:172-96.

88. Lim H-J, Lee G, Yang S-J. The trends in research on the health of North Korean refugees. J Korean Acad Community Health Nurs 2017;28:144-55.

89. Kim SG, Kim KJ, Ha S, et al. A peek into the Galapagos of the medical research field. The Lancet 2016;388:2989-90.

90. Jung $M$, Chung $D$, Choi M. [Keywords network analysis of articles in the North Korean Journal of preventive medicine 1997-2006]. J Prev Med Public Health 2008;41:365-72.

91. Kim OJ. [An analysis of a North Korean Medical Journal: In-Min-BoGun (People's Health) in 1950s]. Uisahak 2002;11:165-85.

92. Bahk J, Ezzati M, Khang YH. The life expectancy gap between North and South Korea from 1993 to 2008. Eur J Public Health 2018;28:830-5.

93. DPR Korea Government. Strategic plan for prevention and control of noncommunicable diseases (2011-2015), 2010. Available: https:// www.tobaccocontrollaws.org/files/live/North\%20Korea/North\% 20Korea\%20-\%20NCD\%20Strategic\%20Plan.pdf

94. DPR Korea Government. Strategy for the prevention and control of non communicable diseases in the Democratic People's Republic of Korea 2014- 2020. Pyongyang: Ministry of Public Health, 2014.

95. DPRK Ministry of Public Health. Comprehensive report of the DPR Korea's national TB prevalence Survey 2015-2016. 2017.

96. National Malaria Elimination Strategy 2018-22. DPR Korea. National Malaria Programme, Ministry of Public Health 2017.

97. Ejov M, Gunasekar A, Hii J. External malaria programme review Dpr Korea. 2017.

98. DPRK Socio-Economic, Demographic and Health Survey 2014. Central Bureau for Statistics and UNFPA. 2015. 